\title{
Prenatal detection and progression of right coronary artery to right ventricle fistula
}

\author{
G K Sharland, M Tynan, S A Qureshi
}

\begin{abstract}
Prenatal diagnosis of a congenital coronary artery fistula between the right coronary artery and right ventricle was made by colour Doppler echocardiography at 20 weeks of gestation. Its progression was monitored by serial echocardiography throughout pregnancy and postnatally.
\end{abstract}

(Heart 1996;76:79-81)

Keywords: coronary artery fistula; prenatal detection

Congenital coronary arteriovenous fistulas are rare. To our knowledge their prenatal detection and progression have not been reported before. We report the prenatal detection of a coronary artery fistula between the right coronary artery and the right ventricle in a fetus at 20 weeks of gestation. Furthermore, we were able to monitor its progression throughout the pregnancy and postnatally.

\section{Case report}

A 40 year old woman was referred for fetal echocardiography at 20 weeks' gestation because an abnormality of the fetal heart was suspected during routine obstetric scanning. On the initial fetal cardiac scan, the fetus was noted to have situs solitus with atrioventricular

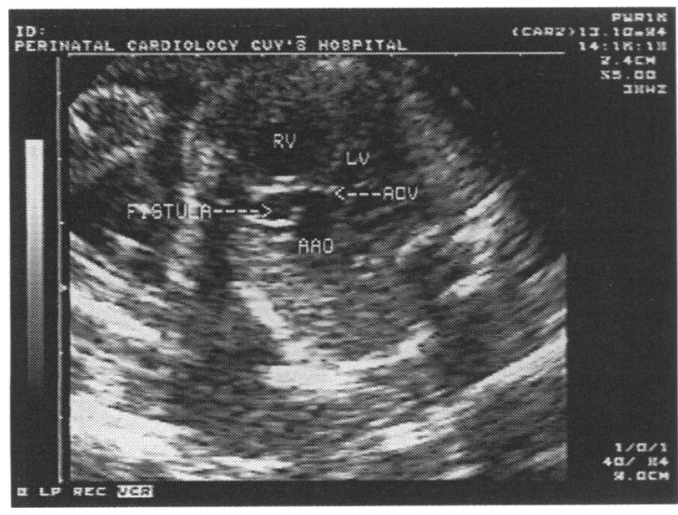

A Figure 1 Cross sectional echocardiogram (A) of fetus at 22 weeks' gestation showing mild aneurysmal dilatation of the
right coronary artery to right ventricle fistula. (B) Colour Doppler flow through the fistula from the ascending aorta into the right ventricle. $A A O$, ascending aorta; $A O V$, aortic valve; $R V$, right ventricle; $L V$, left ventricle.

and ventriculo-arterial concordance. The right atrium and the right ventricle were dilated compared with the left atrium and the left ventricle. The right ventricle had reduced contractility compared with the left ventricle. A high velocity flow $(1.8 \mathrm{~m} / \mathrm{s})$ was detected arising from the side of the ascending aorta, but its destination was not clear. A further scan, performed at 22 weeks' gestation, showed a vessel arising from the side of the ascending aorta and the blood flow within it on colour flow mapping was from the ascending aorta to the right ventricle, consistent with a fistula between the right coronary artery and the right ventricle (fig $1 \mathrm{~A}$ and $\mathrm{B}$ ). Turbulent reversed flow was also detected in the aortic arch in diastole in addition to the forward systolic flow. Repeat scans at 29 weeks and 34 showed that the size of the fistula had increased in relation to the ascending aorta (table 1 ). The fistula also became aneurysmally dilated with advancing gestational age.

The baby was electively delivered at 38 weeks' gestation by normal vaginal delivery. The birth weight was $3 \cdot 1 \mathrm{~kg}$. Postnatally, the echocardiogram confirmed the prenatal diagnosis (fig $2 \mathrm{~A}$ ). She was initially treated conservatively and discharged home two weeks later. At the age of seven weeks, she required diuretic treatment because of congestive cardiac failure. Table 2 shows the echocardiogram measurements.

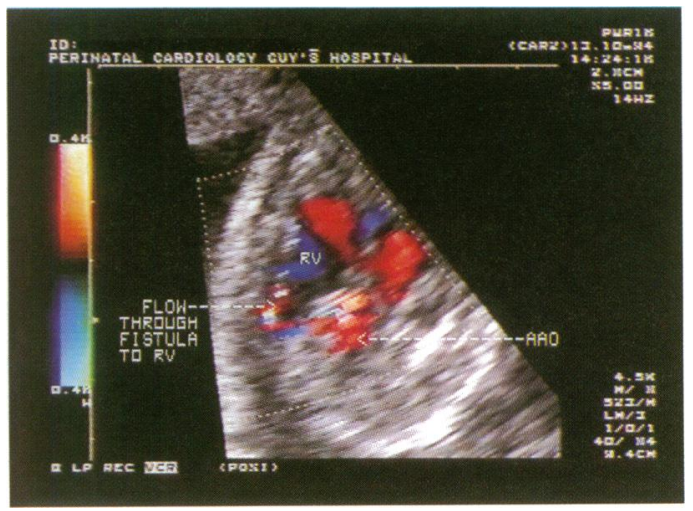

$B$

\author{
Cardiology, 15th Floo \\ Guy's Tower, Guy's \\ Hospital, St Thomas Street \\ Accepted for publication \\ 2 January 1996 \\ Cardiology, Guy's \\ GK Sharland \\ S A Qureshi \\ Correspondence to: \\ Dr G K Sharland,
}

ments of Feta 
Table 1 Prenatal echocardiogram measurements ( $\mathrm{mm}$ )

\begin{tabular}{llll}
\hline Site of measurement & $\begin{array}{l}22 \text { weeks' } \\
\text { gestation }\end{array}$ & $\begin{array}{l}29 \text { weeks' } \\
\text { gestation }\end{array}$ & $\begin{array}{l}34 \text { weeks' } \\
\text { gestation }\end{array}$ \\
\hline Aortic valve & $4 \cdot 0$ & $4 \cdot 7$ & 6 \\
Ascending aorta & $5 \cdot 5$ & 6 & $7 \cdot 2$ \\
Origin of fistula & $3 \cdot 0$ & $4 \cdot 3$ & $5 \cdot 5$ \\
Aneurysm & $4 \cdot 0$ & $6 \cdot 5$ & $9 \cdot 0$ \\
Distal to aneurysm & $2 \cdot 8$ & $3 \cdot 6$ & $4 \cdot 6$ \\
\hline
\end{tabular}

Table 2 Postnatal echocardiogram and angiogram measurements ( $\mathrm{mm}$ )

\begin{tabular}{lccccl}
\hline & \multicolumn{2}{l}{ Echocardiogram } & & \multicolumn{2}{c}{ Angiogram } \\
\cline { 2 - 3 } \cline { 5 - 6 } Site of measurement & Day 1 & 2 weeks & & 2 months & 5 months \\
\hline Aortic valve & 6.7 & 8.2 & 9.2 & - \\
Ascending aorta & 9.5 & 12.0 & & 13.1 & 16.8 \\
Origin of fistula & 6.9 & 7.3 & & 8.0 & 10.5 \\
Aneurysm & $12 \mathrm{~mm}$ & $13.5 \mathrm{~mm}$ & $14.0 \mathrm{~mm}$ & $16.5 \mathrm{~mm}$ \\
Distal to aneurysm & 8 & 8.5 & & 9.0 & 10.0 \\
& & & & (minimum dimension \\
& & & & $=7.5 \mathrm{~mm}$ ) \\
\hline
\end{tabular}

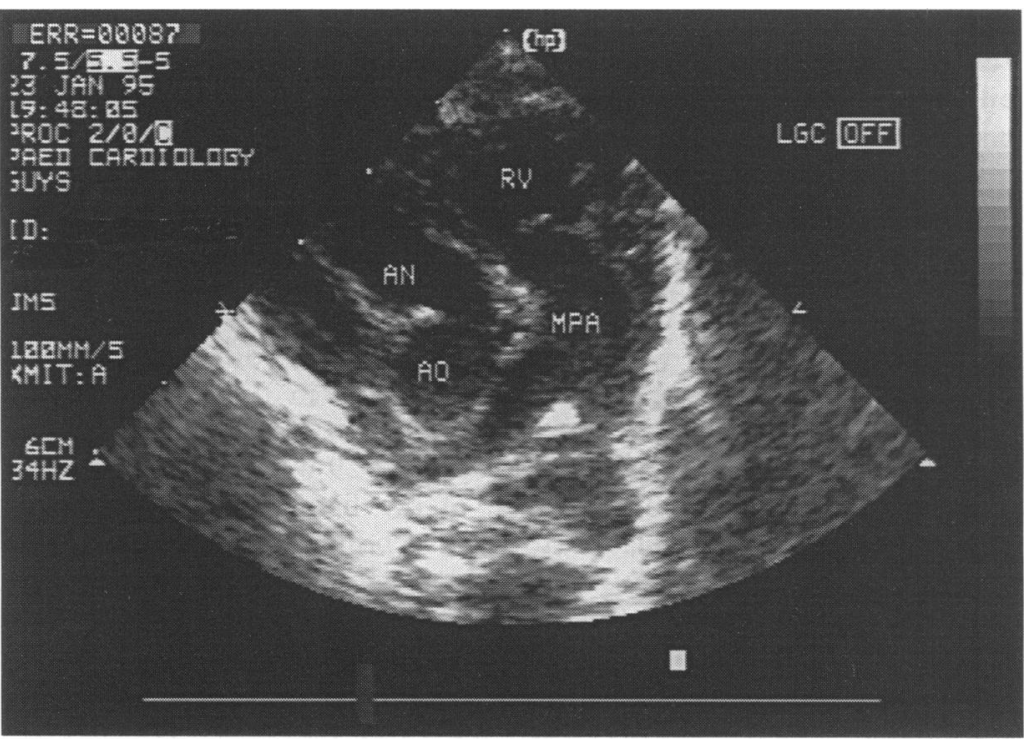

$A$
At five months of age, because of continuing breathlessness, failure to thrive, and Doppler evidence of continuing pulmonary hypertension, transcatheter coil embolisation of the coronary artery fistula was performed by retrograde femoral artery catheterisation. Both the femoral arteries were cannulated and angiograms obtained (fig 2B). Table 2 shows the measurements of the fistula on angiography. A 5 Fr Berman balloon catheter was placed through one of the femoral artery sheaths in the fistula at the site of the stenosis and the balloon was kept inflated. Through the other femoral artery, a guiding catheter was placed in the aneurysmal part of the fistula, and five controlled release Jackson coils (two of $12 \mathrm{~mm}$ diameter and three of $10 \mathrm{~mm}$ diameter) were implanted. One of the $10 \mathrm{~mm}$ coils embolised at the end of the procedure to the right ventricle and subsequently to the right pulmonary artery. Because of large residual flow, three interlocking detachable coils of 8 $\mathrm{mm}$ diameter were also placed in the fistula alongside the previous coils (fig 2C). Before embolisation, the main pulmonary artery pressure was $85 / 47 \mathrm{~mm} \mathrm{Hg}$ compared with systemic arterial pressure of $95 / 38 \mathrm{~mm} \mathrm{Hg}$. After embolisation, the main pulmonary artery pressure was $50 / 20 \mathrm{~mm} \mathrm{Hg}$ compared with systemic arterial pressure of $75 / 30 \mathrm{~mm} \mathrm{Hg}$. Five hours later, the infant sustained a cardiac arrest owing to ventricular fibrillation. A chest $x$ ray confirmed that one of the coils had moved from the right ventricle to the right pulmonary artery. She subsequently became hypotensive and could not be resuscitated. At necropsy the remaining coils were in a satisfactory position in the fistula. There was no rupture of the aneurysm. There was no pulmonary infarction, but severe lymphangiectasia was noted in both the lungs. The right ventricle was hypertrophied but there was no evidence of myocardial infarction.

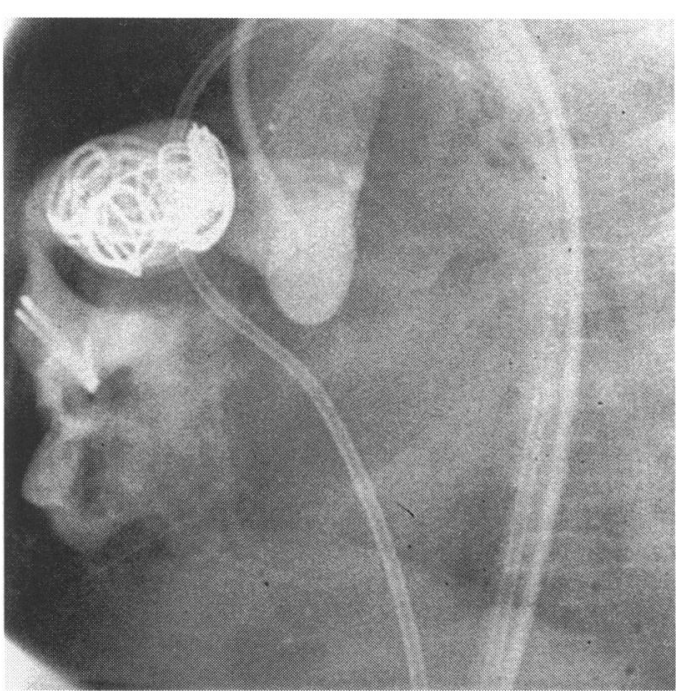

$C$

Figure 2 (A) Postnatal echocardiogram on day 1 showing considerable dilatation of the coronary artery fistula. See legend to fig 1 for abbreviations. AN, aneurysm; $A O$, aorta; $M P A$, main pulmonary artery. (B) Right coronary angiogram in the left lateral projection showing aneurysmal dilatation of the fistula that arises from right coronary artery and drains to the right ventricle by a narrow aperture (arrow). (C) Aortogram in the left lateral projection showing a coil embolised to the right ventricle and all the other coils in the aneurysmal part of the fistula. There was still some residual flow through the coils. 


\section{Discussion}

Coronary arteriovenous fistulas are rare. Very few patients develop symptoms of congestive cardiac failure from a large left-to-right shunt or myocardial ischaemia from coronary artery steal in the first few years after birth. However, after the second decade, the frequency of symptoms and complications increases. ${ }^{1}$ These fistulas are the commonest haemodynamically significant coronary artery anomaly. ${ }^{2}$ Usually the fistula is formed by a single coronary artery, which is dilated, has a long tortuous course around the heart, and drains into a cardiac chamber or a nearby vessel. Therefore the fistulas may drain into the right atrium, caval veins, coronary sinus, right ventricle, and the pulmonary trunk. The aneurysmal portion of the fistula may progressively dilate and the artery may become tortuous with time. The other complications include thrombosis and embolism, congestive cardiac failure, atrial fibrillation and other arrhythmias, endocarditis, and rupture of the fistula. ${ }^{2-5}$ Therefore closure of these fistulas is recommended, often even in the absence of symptoms. The usual treatment has been surgery, but over the last few years, transcatheter non-surgical embolisation using coils and detachable balloons has become the preferred option. ${ }^{5}$

Some fistulas are already large in the neonatal period or early infancy. Others may progressively increase in size over a period of years. Rarely, some fistulas that are small to begin with may undergo spontaneous closure. ${ }^{6}$ In our patient a coronary artery fistula was detected at 20 weeks of gestation. During the course of the pregnancy, there was a progressive increase in size as well as tortuosity of the fistula. Postnatally, during the follow up period, some stenosis had developed at one of the bends, but this was not sufficient to reduce the left-to-right shunt. Because the infant continued to fail to thrive and had congestive cardiac failure and pulmonary hypertension, transcatheter coil embolisation was attempted and despite coil implantation, resulting in reduction of the pulmonary blood flow and the pulmonary artery pressures, the infant died soon after an episode of ventricular fibrillation. This episode may have been related to migration of one of the coils through the right ventricle into the right pulmonary artery.

The prenatal echocardiographic features included a dilated right ventricle with impaired contractility associated with a dilated right coronary artery, in which colour flow was seen passing from the ascending aorta to the right ventricle. Evidence of a significant diastolic run-off in the ascending aorta was provided by the presence of reversed colour flow in the transverse aortic arch, an extremely rare finding in the fetus.

Our case is noteworthy because it is the first time that a coronary artery fistula has been detected in utero, at 20 weeks gestation, and because we were able to document its progression through pregnancy and postnatally.

1 Liberthson RR, Sagar K, Berkoben JP, Weintraub RM, Levine FH. Congenital coronary arteriovenous fistula: report of 13 patients, review of the literature and delineation of management. Circulation 1979;59:849-54.

2 Wilde P, Watt I. Congenital coronary artery fistulae: six new cases with a collective review. Clinical Radiology 1980;31:301-11.

3 St John Sutton MG, Miller GA, Kerr IH, Traill TA Coronary steal via large coronary artery to bronchial artery anastomosis successfully treated by operation. $B r$ Heart $¥ 1980 ; 44: 460-3$.

4 Moro-Serrano C, Martinez J, Madrid AH, Rufilanchas JI, Novo L, Marin Huerta E, et al. Ventricular tachycardia in Novo L, Marin Huerta E, et al. Ventricular tachycardia in a patient with congenital coron

5 Reidy JF, Anjos RT, Qureshi SA, Baker EJ, Tynan MJ. Transcatheter embolization in the treatment of coronary Transcatheter embolization in the treatment of corct
artery fistulas. $\mathcal{F} \mathrm{Am}$ Coll Cardiol 1991;18:187-92.

6 Hackett D, Hallidie-Smith KA. Spontaneous closure of coronary artery-cardiac chamber fistula. Br Heart $\mathcal{f} 1984$ 54:477-9. 